\title{
Direct Syngas Hydrogenation Over a Co-Ni Bimetallic Catalyst: Process Parameter Optimization
}

\author{
Karthikeyan K. Ramasamy ${ }^{\text {a }}$, Michel Gray ${ }^{\mathrm{a}, *}$, Heather Job ${ }^{\text {a }}$, Yong Wang ${ }^{\mathrm{a}, \mathrm{b}, *}$ \\ ${ }^{a}$ Chemical and Biological Process Development Group, \\ Pacific Northwest National Laboratory, Richland, Washington 99354, USA. \\ ${ }^{b}$ The Gene and Linda Voiland School of Chemical Engineering and Bioengineering, \\ Washington State University, Pullman, Washington 99164-2710, USA.
}

* Corresponding authors:

${ }^{a}$ Pacific Northwest National Laboratory, Richland, Washington 99354, USA.

E-mail: michel.gray@pnnl.gov; Phone: 509-375-4549

${ }^{\mathrm{b}}$ Washington State University, Pullman, Washington 99164-2710, USA.

E-mail: yong.wang@pnnl.gov; Phone: 509-539-4850

\begin{abstract}
The syngas hydrogenation activity of the Co-Ni bimetallic catalyst containing total metal loading less than $10 \mathrm{wt} \%$ was prepared via a wet impregnation method and was studied with respect to the reaction temperature and the catalyst composition. Among the hydrocarbons generated, small olefinic compounds between $\mathrm{C}_{2}$ and $\mathrm{C}_{7}$ (up to $40 \%$ ) were the highest in the product mixture. The olefin to paraffin ratio for $\mathrm{C}_{3}$ hydrocarbon is around 8 . For all variables tested, the product distribution contains up to $10 \%$ oxygenates along with the hydrocarbon compounds. An acidic alumina containing reactor was added followed by the Co-Ni containing reactor to demonstrate the deoxygenation of oxygenates generated from the FTS process to improve the small olefinic fraction and the overall carbon yield to the valuable products.
\end{abstract}

Keywords: Syngas conversion, Bimetallic catalyst, Fischer-Tropsch, Co-Ni, Renewable fuel

\section{Introduction}

The projected depletion of crude oil resources and the potential contribution of fossil energy resources to greenhouse gas emissions drew attention to the need to develop renewable energy technologies. Fischer-Tropsch synthesis (FTS) is one of the most technologically feasible processes for producing transportation fuels from a range of feed stocks such as natural gas, coal, municipal solid waste, and biomass (Enger and Holmen, 2012; Ramasamy et al., 2014). Efforts to synthesize hydrocarbons through the catalytic hydrogenation of carbon monoxide (CO) date 


\section{Revised Manuscript}

back to 1902, when Sabatier and Senderens synthesized hydrocarbons from CO and hydrogen $\left(\mathrm{H}_{2}\right)$ (Calderone et al., 2011).

Catalysts made up of cobalt ( $\mathrm{Co}$ ) and iron (Fe) are the most commonly used catalysts in the FTS process. Co-based catalysts are generally more active and more selective to linear long chain hydrocarbons, and are typically more resistant to deactivation by water, but require a complex matrix of downstream unit operations, such as cracking and isomerization, to generate the finished fuel, which can be very expensive (Jahangiri et al., 2014). Fe-based catalysts can be operated under wider ranges of temperatures and $\mathrm{H}_{2} / \mathrm{CO}$ ratios without a significant rise in methane $\left(\mathrm{CH}_{4}\right)$ selectivity; these catalysts are inexpensive compared to Co. However, Fe catalysts generate high levels of gasoline range products and $\mathrm{C}_{2}-\mathrm{C}_{5}$ olefinic compounds, and they rapidly deactivate to make costs unfavorable from the commercial point of view (de Smit and Weckhuysen, 2008). The tendencies of the nickel (Ni) catalyst to generate high levels of $\mathrm{CH}_{4}$ via methanation chemistry and form volatile carbonyls resulting in the continuous loss of metal at the FTS operating conditions made Ni unsuitable for the commercial FTS process (Dry, 2004 p.533; Enger and Holmen, 2012). Recently, Rytter et al. (2010) identified Ni as a suitable replacement for rhenium $(\mathrm{Re})$ as a reduction and activity promoter to their Co catalyst in the FTS process. They reported the presence of $\mathrm{Ni}$ has a profound positive impact on the catalytic activity, as well as the start of run activity, steady-state level, and deactivation rate.

For several decades, researchers have struggled with optimizing FTS catalysts to control product selectivity and overcome catalyst deactivation. FTS performance depends on the catalyst composition, preparation methods, treatment parameters, and reaction operating parameters (Calderone et al., 2011). Recently, several groups have explored using bimetallic catalysts to control selectivity and suppress deactivation. Most studies using bimetallic catalysts have focused on a combination of the conventional FTS metals ( $\mathrm{Co}, \mathrm{Ni}, \mathrm{Fe}$, and $\mathrm{Ru}$ ) (Calderone et al., 2011), both bimetallic and ternary, with respect to the alloy formation, metal support interaction, promoter effect, and catalyst synthesis and activation techniques to selectively generate liquid fuel mixtures with a high carbon yield in fewer reaction steps.

One current interest is the generation of small olefin compounds that can be oligomerized to the targeted fuel or chemical compounds (Torres Galvis and de Jong, 2013). As discussed previously, Fe catalyst always exhibits high levels of olefin composition, but also generates high levels of $\mathrm{CO}_{2}$, along with carbon formation on the catalyst. Literature also points out that a Comanganese- $(\mathrm{Mn})$ based catalyst can have the potential to generate a high olefin composition with low levels of $\mathrm{CO}_{2}$ and $\mathrm{CH}_{4}$; this is still in the early stages of research (Zhou et al., 2015; Liang et al., 1998). This information, combined with some of our preliminary results from the $\mathrm{Co}-\mathrm{Ni}$ bimetallic catalyst on the $\mathrm{CO}$ hydrogenation, led us to further explore and understand the ability of Co-Ni to generate hydrocarbon compounds containing high levels of a small olefin fraction. In this paper, the bimetallic Co-Ni catalyst activity and the product selectivity towards small olefins from the syngas $\left(\mathrm{CO}+\mathrm{H}_{2}\right)$ conversion with respect to the catalyst metal loading and reaction temperature will be discussed based on the experimental results. In addition, this paper will introduce a dual bed configuration to convert oxygenates generated in the $\mathrm{CO}$ hydrogenation process to produce targeted hydrocarbon compounds. 


\section{Experimental}

\subsection{Catalyst Preparation}

Bimetallic catalyst preparation uses cobalt nitrate/nickel nitrate and Davisil Silica 645 (purchased from Sigma-Aldrich). Co-Ni catalysts are prepared by incipient wetness impregnation of silica $\left(\mathrm{SiO}_{2}\right)$ support $\left(60 / 100\right.$ mesh, pre-calcined at $\left.500{ }^{\circ} \mathrm{C}\right)$. The appropriate quantities of a cobalt nitrate solution and a nickel nitrate solution were combined with enough deionized water to bring the total volume of the impregnation solution to $90 \%$ of the water adsorption pore volume of the silica support. The solution was impregnated onto the support in drop-wise fashion on a vibrating table to keep the support solids in motion during impregnation. The impregnated catalysts were dried under an infrared lamp while being shaken until a steady weight was achieved, and then they were dried overnight at $110{ }^{\circ} \mathrm{C}$ in a drying oven. Unless mentioned, $2.9 \mathrm{wt} \%$ Co and $2.9 \mathrm{wt} \% \mathrm{Ni}$ metal loading was used in most of these experiments. Higher metal loading catalysts (metal loading 12\%) were prepared using two impregnations, with drying between impregnations. Each impregnation solution volume, containing the appropriate metal concentrations, was equal to $90 \%$ of the water adsorption pore volume of the support. The dried catalysts impregnated on the silica support were calcined at $350{ }^{\circ} \mathrm{C}$ in air, using a muffle furnace. Before conducting the $\mathrm{CO}$ hydrogenation tests, the calcined (or dried) catalysts were loaded into the reactor and reduced in a $10 \mathrm{vol} \% \mathrm{H}_{2}$ balance nitrogen $\left(\mathrm{N}_{2}\right)$ gas mixture atmosphere. All the catalysts were heated in the reducing atmosphere to $220{ }^{\circ} \mathrm{C}$ at a $2.5^{\circ} \mathrm{C} / \mathrm{min}$ ramp-up rate, and held at that temperature for 1 hour. After the initial heating, the catalysts were then heated from $220{ }^{\circ} \mathrm{C}$ to $260{ }^{\circ} \mathrm{C}$ at a rate of $1{ }^{\circ} \mathrm{C} / \mathrm{min}$, and held at that temperature for 8 hours; the catalysts were then heated to approximately $350{ }^{\circ} \mathrm{C}$ at a rate of $1.5^{\circ} \mathrm{C} / \mathrm{min}$, and held at that temperature for 2 hours.

\subsection{Catalyst Characterization}

X-ray powder diffraction (XRD) patterns of all calcined samples were recorded on a Phillips XPert $(50 \mathrm{kV}$ and $40 \mathrm{~mA})$ diffractometer using $\mathrm{Cu} \mathrm{K} \alpha$ radiation $(\lambda=1.5437 \AA)$. Each sample was scanned in the range between $30^{\circ}$ and $80^{\circ}$. The reducibility of the catalysts was studied by $\mathrm{H}_{2}$ temperature programmed reduction $\left(\mathrm{H}_{2}-\mathrm{TPR}\right)$. About $100 \mathrm{mg}$ of catalyst was loaded in a quartz tube and heated to $350{ }^{\circ} \mathrm{C}$ at a ramp rate of $2{ }^{\circ} \mathrm{C} / \mathrm{min}$ in a helium (He) stream with a flow rate of $25 \mathrm{~mL} / \mathrm{min}$ and held at that temperature for 2 hours. After being cooled to room temperature, the carrier gas was replaced by a $9.8 \% \mathrm{H}_{2} /$ Argon (Ar) with a flow rate of $25 \mathrm{~mL} / \mathrm{min}$. The temperature was raised from room temperature to $800{ }^{\circ} \mathrm{C}$ at a ramp rate of $10{ }^{\circ} \mathrm{C} / \mathrm{min}$ and held for $5 \mathrm{~min}$ at $800^{\circ} \mathrm{C}$. The off-gas was analyzed on a Micromeretics Autochem II equipped with a PFEIFFER mass spectrometer to get the reduction profile of the catalysts. Surface area, porosity, and pore size analyses were determined using $\mathrm{N}_{2}$ adsorption/desorption collected with a QUANTACHROME AUTOSORB 6-B gas sorption system. The samples were degassed at $100{ }^{\circ} \mathrm{C}$ for approximately 10 hours under vacuum. The $\mathrm{N}_{2}$ adsorption/desorption at a constant temperature of $77.4 \mathrm{~K}$ was conducted on the degassed samples. The volume amount of $\mathrm{N}_{2}$ gas that adsorbed/desorption onto the surface of sample vs. relative pressure was measured (isotherm). The surface area was determined using adsorption data at $\mathrm{p} / \mathrm{p}_{\mathrm{o}}$ value between 0.1 and 0.3 using the BET (Brunauer-Emmett-Teller) method. The BJH (Barrett-Joyner-Halenda) method was used for the porosity and pore size analyses. 


\subsection{Catalyst Testing}

A schematic diagram of the syngas conversion catalyst testing unit is shown in Figure 1. The test stand is composed of a dual fixed-bed reactor system for heterogeneous catalyst testing. The system consists of a gas feed system, two heated reactor systems arranged in series, and a gasliquid separation system. The gas feed system consists of a manifold for feeding $\mathrm{N}_{2}$, syngas, $\mathrm{H}_{2}$ or a reducing gas mixture $\left(10 \mathrm{vol} \% \mathrm{H}_{2}\right.$ balance $\left.\mathrm{N}_{2}\right)$, and $\mathrm{CO}$ through separate mass flow control valves. A feed reactant syngas mixture is purchased from Oxarc as a 2:1 ratio (gas mixture contains $4 \mathrm{vol} \% \mathrm{~N}_{2}$ as an inert standard). $\mathrm{CO}$ can be used to vary the $\mathrm{H}_{2}$ to $\mathrm{CO}$ ratio in conjunction with the syngas or $\mathrm{H}_{2}$. The feed gas prior to introduction into the reactor system was preheated as they pass through the heated reactor system.

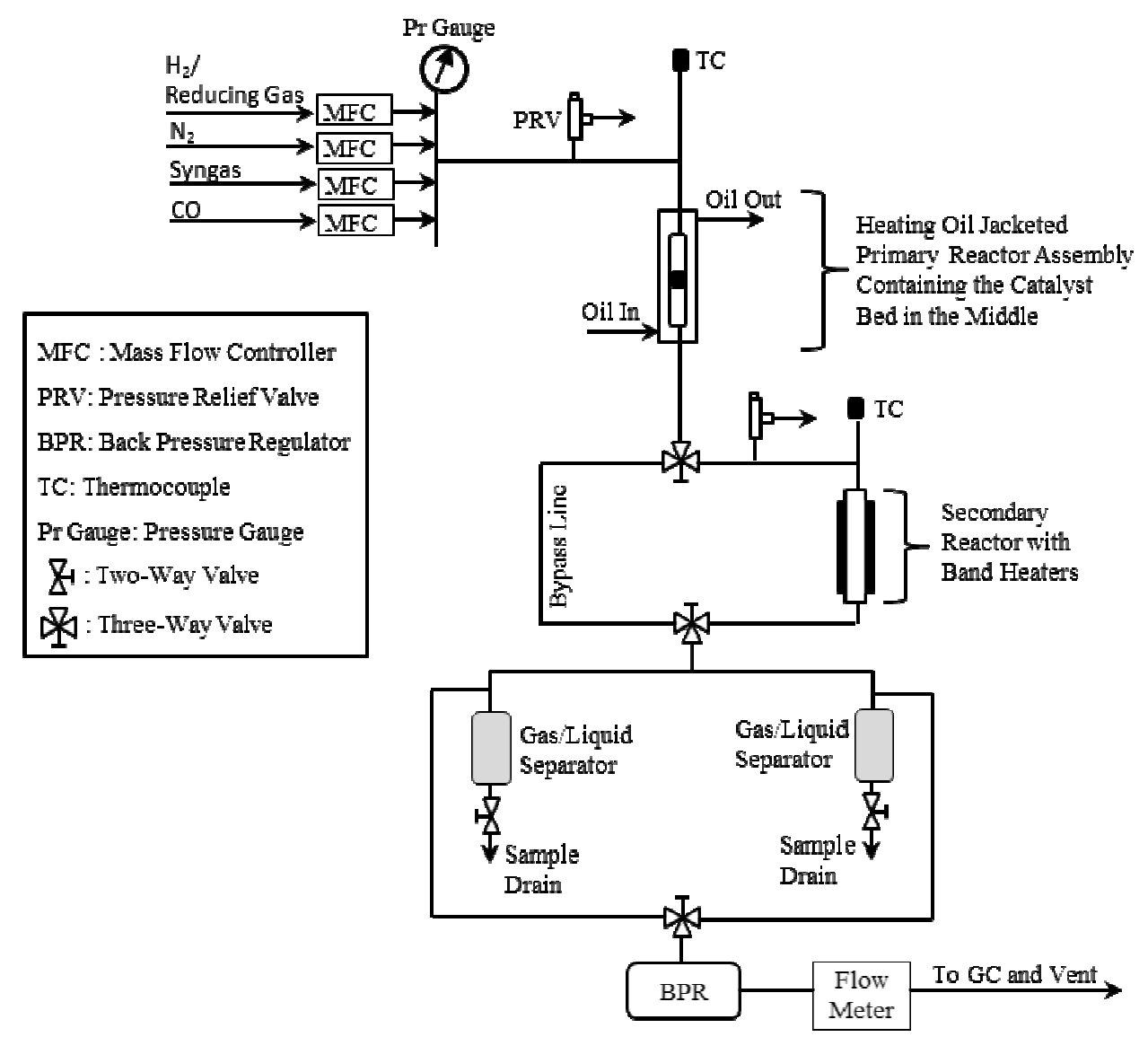

Fig.1. Process flow diagram of the experimental setup utilized in the syngas conversion catalyst testing.

The heated reactor system consists of two reactor subsystems - a primary reactor system and a secondary reactor system. The primary reactor system consists of a section of tube containing a bored-through bulkhead union where the catalyst is located (the reactor). The primary reactor is normally enclosed within an oil heated jacket. A thermocouple is located within the catalyst bed to monitor the reaction temperature. The secondary reactor consists of appropriately sized tubing, a portion of which serves as the reactor section and contains the catalyst. This reactor section is heated by a band heater. There is a bypass line in the secondary reactor system to allow 


\section{Revised Manuscript}

the product stream from the primary reactor system to bypass the secondary reactor. This line can be used throughout the test, or periodically during a test, to collect the product from the primary reactor. When the bypass line is being used, the secondary reactor can be isolated and removed from service. The gas-liquid separator system is used to cool and separate the gaseous products from the liquid products exiting the heated reactor system, and collecting samples of each for analysis during a test. Once the reactant gases pass through one or both reactors, the product stream passes through one of two pressurized, chilled, liquid/gas cold traps placed in parallel downstream of the heated reactor system. The dry off-gas is then passed through the back-pressure regulator where the pressure is reduced to atmospheric pressure. The gas then passes through a gas flow meter and is vented to the top of the enclosure. Periodically, gas samples for gas chromatography (GC) analysis (Inficon Micro GC) are obtained from the cool dry gas located downstream of the back-pressure regulator using the GC sampling system. At various points in the process, the liquid products are collected from the liquid/gas cold traps and the aqueous phase liquid product is analyzed by high performance liquid chromatography (HPLC) and the organic phase liquid product is analyzed by gas chromatography mass spectrometry (GC-MS). The dual bed reactor test stand is designed to operate at up to 90 atm $(1,350 \mathrm{psig})$, with a maximum catalyst temperature up to $500{ }^{\circ} \mathrm{C}$.

\section{Results and Discussion}

\subsection{Catalyst Characterization}

The phase structure of the unreduced catalysts (calcined at $350{ }^{\circ} \mathrm{C}$ ) was analyzed using XRD. The powder XRD patterns of the $\mathrm{Ni}$ and $\mathrm{Co}$ oxides at different compositions supported on $\mathrm{SiO}_{2}$ is shown in Figure 2. The monometallic Ni catalyst comprises a primarily cubic NiO phase and the monometallic Co catalyst comprises a primarily cubic $\mathrm{Co}_{3} \mathrm{O}_{4}$ phase. For the Co-Ni bimetallic catalyst, a cubic $\mathrm{NiCo}_{2} \mathrm{O}_{4}$ phase dominates. In the Co-Ni bimetallic catalyst, nickel oxides and cobalt oxides are potentially present. Due to the similarity in structural feature and the close position of diffraction peaks between $\mathrm{NiCo}_{2} \mathrm{O}_{4}, \mathrm{Co}_{3} \mathrm{O}_{4}$, and $\mathrm{NiO}$, distinguishing between these three phases is very difficult (Chang et al., 2012; Li et al., 2012). Based on the XRD data, the particle size of metal oxides can be estimated by using Scherrer's equation. The calculated particle size values are listed in Table 1. The average particle ranged between $12 \mathrm{~nm}$ and $18 \mathrm{~nm}$ for the monometallic and bimetallic catalysts.

The $\mathrm{H}_{2}$-TPR profile of the samples containing different $\mathrm{Co}$ and $\mathrm{Ni}$ composition supported on $\mathrm{SiO}_{2}$ is shown Figure 3. According to the characteristic two step reduction process $\mathrm{Co}_{3} \mathrm{O}_{4} \rightarrow \mathrm{CoO}$ $\rightarrow \mathrm{Co}^{0}$, the monometallic $\mathrm{Co}$ oxide supported on $\mathrm{SiO}_{2}$ presented with two reduction peaks at 250 ${ }^{\circ} \mathrm{C}$ and $300{ }^{\circ} \mathrm{C}$ with an intensity ratio close to $1: 4$. The third broad shoulder peak between $450{ }^{\circ} \mathrm{C}$ and $650{ }^{\circ} \mathrm{C}$ is associated with the reduction of the $\mathrm{Co}$ oxides interacted with the support $\mathrm{SiO}_{2}$ material (Oliveira et al., 2012; vanSteen et al., 1996). The monometallic Ni oxide supported on $\mathrm{SiO}_{2}$ profile showed the characteristic $\mathrm{NiO}$ reduction peak at $300^{\circ} \mathrm{C}$ with the one step reduction process $\mathrm{NiO} \rightarrow \mathrm{Ni}^{0}$. For the bimetallic $2.9 \% \mathrm{Co}-2.9 \% \mathrm{Ni}$ supported on $\mathrm{SiO}_{2}$ sample showed a profile with overlapped reduction peaks of both nickel and cobalt oxide species. In particular, the first peak of the cobalt reduction appeared at $170{ }^{\circ} \mathrm{C}$, significantly lower than that observed in the monometallic Co supported on $\mathrm{SiO}_{2}$. Followed by the second peak a broad peak with maximum at $450{ }^{\circ} \mathrm{C}$ assigned to the reduction of $\mathrm{NiCo}_{2} \mathrm{O}_{4}$. For the $5.8 \% \mathrm{Co}-5.8 \% \mathrm{Ni}$ supported on $\mathrm{SiO}_{2}$ 
catalyst all three peaks were stronger, broader and the peak maximum was shifted slightly to the higher temperature compared to the lower metal loading bimetallic catalyst. In agreement with the XRD analysis, this is most likely because of the smaller particle dimensions of the $\mathrm{NiCo}_{2} \mathrm{O}_{4}$ species (Luisetto et al., 2012). TPR analysis of catalysts clearly showed that in the bimetallic sample the $\mathrm{Co}-\mathrm{Ni}$ alloy is formed in comparison with those of $\mathrm{Co}^{0}$ and $\mathrm{Ni}^{0}$ formation in monometallic samples. Surface area and pore volume for the different catalysts are listed in Table 1. The surface area and pore volume values are in the same range for all the materials tested with small variations.

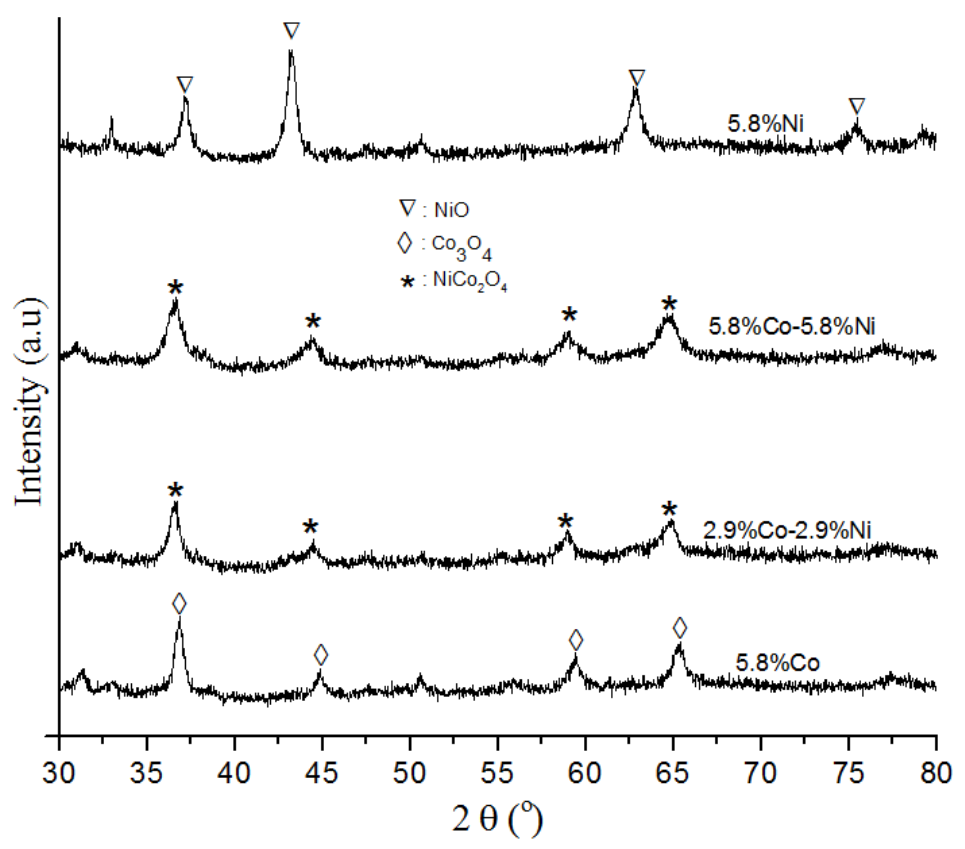

Fig. 2. XRD patterns of the calcined catalysts at different Co-Ni compositions.

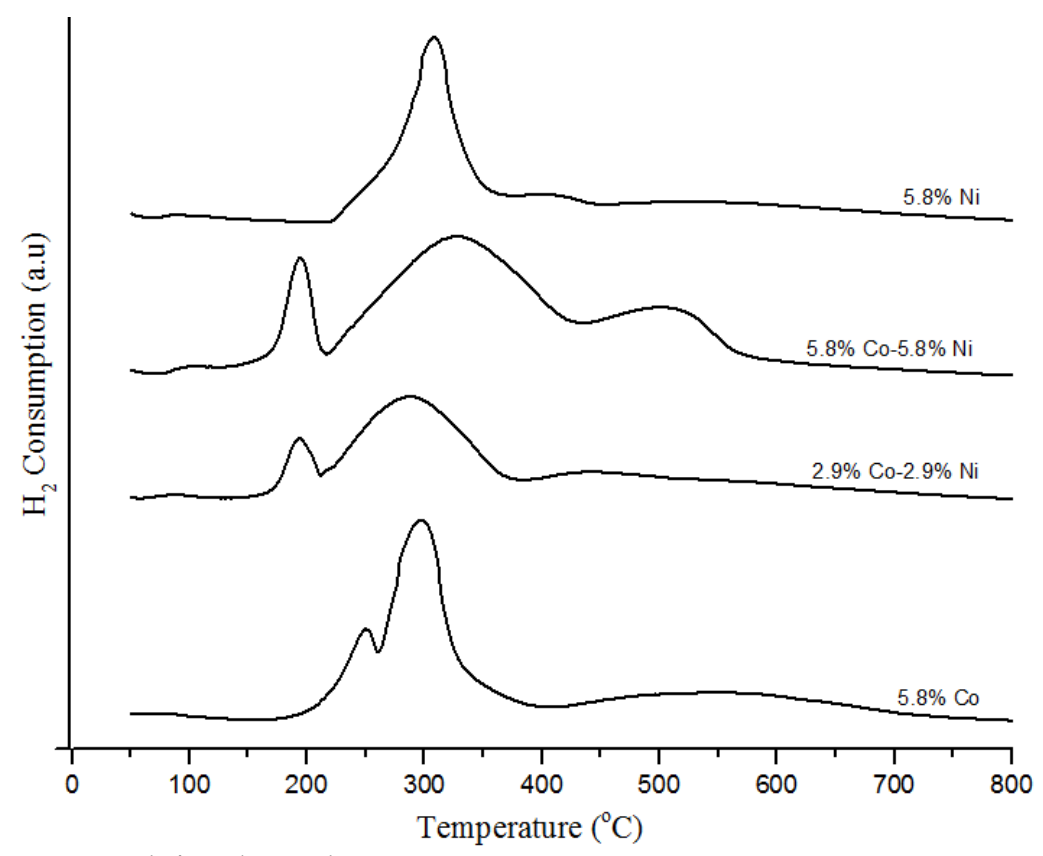

Fig. 3. TPR profile of the calcined catalysts with different Co and Ni composition. 
Table 1. Physical Properties of the calcined catalysts with different Co-Ni compositions

\begin{tabular}{lccc}
\hline \multirow{2}{*}{ Catalyst } & BET Surface Area & BJH Pore Volume & Particle Size $^{*}$ \\
\cline { 2 - 4 } & $\mathbf{~ m}^{\mathbf{2} / \mathbf{g}}$ & $\mathbf{\mathbf { c m } ^ { 3 } / \mathbf { g }}$ & $\mathbf{n m}$ \\
\hline $5.8 \% \mathrm{Co}$ & 249.2 & 1.03 & 17.5 \\
$2.9 \% \mathrm{Co}-2.9 \% \mathrm{Ni}$ & 255.8 & 1.05 & 14.4 \\
$5.8 \% \mathrm{Co}-5.8 \% \mathrm{Ni}$ & 234.1 & 0.94 & 12.7 \\
$5.8 \% \mathrm{Ni}$ & 264.3 & 1.09 & 15.8 \\
\hline${ }^{*}$ The mean size of the metal oxides derived from XRD using Scherrer's equation
\end{tabular}

\subsection{Bimetallic Effect}

The reaction mechanism for the FTS process is very complicated; it is now generally accepted that FTS chemistry proceeds through a surface catalyzed polymerization mechanism, which uses $\mathrm{CHx}$ monomers formed by the hydrogenation of CO. Detailed FTS reaction mechanism studies can be found in many research and review articles (Zhang et al., 2010; Roferdepoorter, 1981). The influence of the $\mathrm{CO}$ hydrogenation product selectivity and the $\mathrm{CO}$ conversion is strongly related to the influence of the process conditions and catalyst composition. Therefore, this work is focused on understanding the Co-Ni bimetallic catalyst activity and product selectivity with respect to the operating conditions and catalyst composition variables. The FTS process generates a multicomponent complex mixture with a range of carbon number and product type.

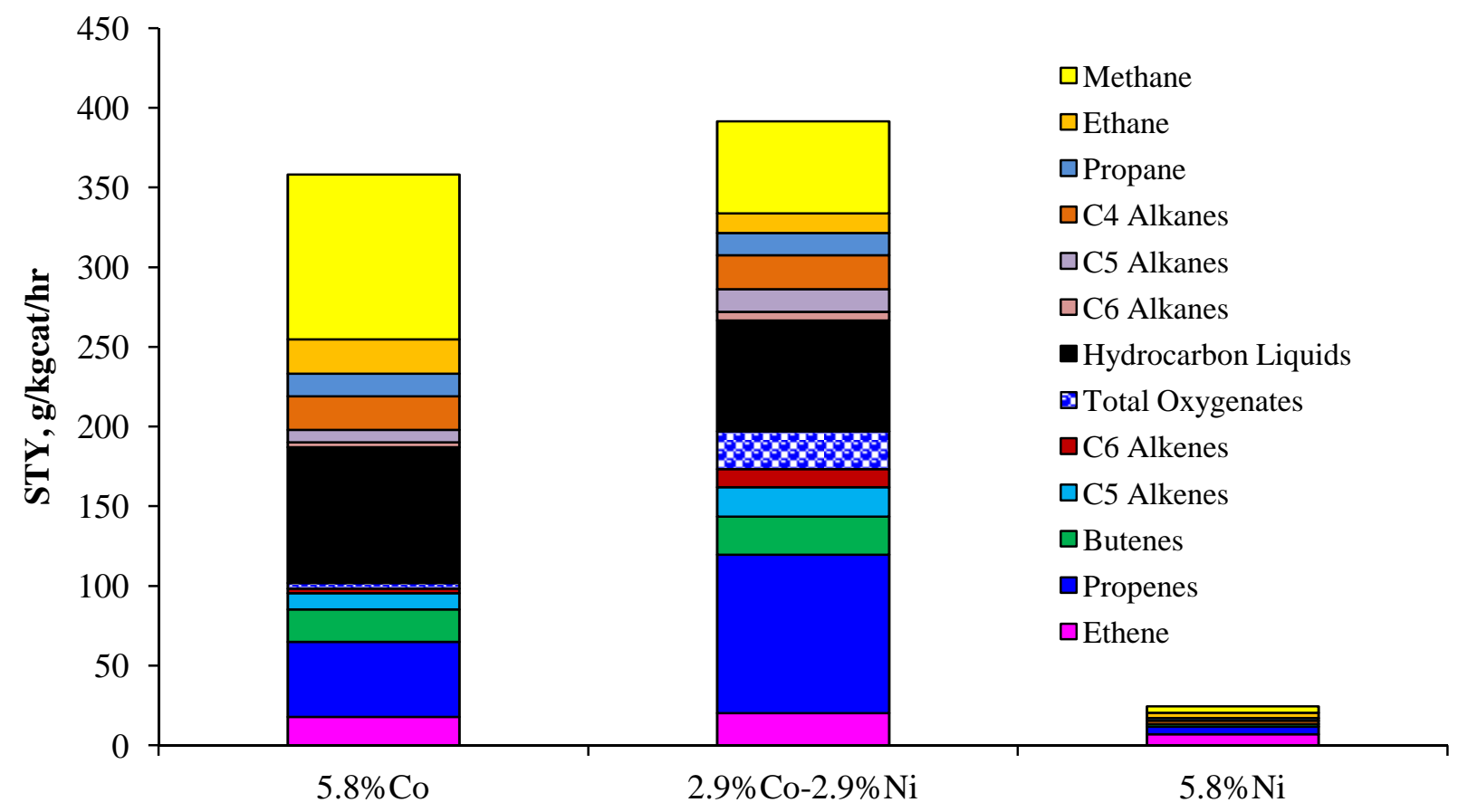

Fig. 4. STY and the product distribution of the syngas hydrogenation over monometallic Co, Ni and bimetallic Co-Ni catalysts, $\mathrm{H}_{2}$ to $\mathrm{CO}$ ratio 2, $285^{\circ} \mathrm{C}$, GHSV $12000 \mathrm{~L} / \mathrm{Kg} / \mathrm{hr}$, and 1200 psi operating conditions. 


\section{Revised Manuscript}

The FTS product composition primarily includes paraffins, olefins, and different classes of oxygenates (among the oxygenates, alcohols comprise the major fraction). One of the primary interests in this research is to generate a higher olefin fraction, which can then be further oligomerized to generate the target transportation fuel or chemicals and reduce/avoid the $\mathrm{CH}_{4}$ and $\mathrm{CO}_{2}$ formation from the syngas hydrogenation. In the earlier sections, we have presented the advantages and disadvantages of the various syngas hydrogenation catalysts. To show the rationale for the $\mathrm{Co}-\mathrm{Ni}$ bimetallic catalysts, experiments were conducted on monometallic $\mathrm{Co}$, $\mathrm{Ni}$, and bimetallic Co-Ni catalysts with $\mathrm{H}_{2}$ to $\mathrm{CO}$ ratio $2,285^{\circ} \mathrm{C}$, GHSV $12000 \mathrm{~L} / \mathrm{Kg} / \mathrm{hr}$, and 1200 psi operating conditions and compared the space time yields (STY), and the product class distribution from the syngas hydrogenation experiment (shown in Figure 4). The monometallic $\mathrm{Ni}$ catalyst is considered to be very active for the methanation reaction $\mathrm{CO}+3 \mathrm{H}_{2} \rightarrow \mathrm{CH}_{4}+\mathrm{H}_{2} \mathrm{O}$, but it shows almost no activity at the operating conditions tested. This is because the operating temperature, pressure, catalyst metal loading, and the $\mathrm{H}_{2}$ to $\mathrm{CO}$ ratio used in this experiment were not optimum for the methanation chemistry (Zhao et al, 2012; Hu et al., 2012). At optimal conditions, Co-based catalysts (> 10\% metal loading, around $200{ }^{\circ} \mathrm{C}$ temperature and around 300 psig pressure) typically produce linear long chain alkanes (Zhang et al., 2010 and Gnanamani et al., 2013). The tested conditions were not optimal for the Co-based FTS process, yet even at these conditions, the products generated were high in paraffinic compounds (in $\mathrm{C}_{5}+$ range) along with high methane selectivity. The bimetallic Co-Ni catalyst with total metal loading of 5.8\% generated less methane (approximately 15\% carbon selectivity) as well as a higher olefinic to paraffinic ratio, and it aligns with our expectations to generate olefinic rich stream. Further optimization with respect to the conditions, such as operating temperature and metal loading, will be discussed in the sections below.

\subsection{Temperature Effect}

The initial FTS experiments were carried out over a range of temperatures between $280{ }^{\circ} \mathrm{C}$ and $300{ }^{\circ} \mathrm{C}$ on the $2.9 \% \mathrm{Co}-2.9 \% \mathrm{Ni}$ on $\mathrm{SiO}_{2}$ catalyst at $1200 \mathrm{psi}, \mathrm{H}_{2}$ to $\mathrm{CO}$ ratio of 2 , and gas hourly space velocity (GHSV) of $12000 \mathrm{~L} / \mathrm{Kg} / \mathrm{hr}$. The STY, CO conversion, and detailed product selectivity are shown in Figure 5 and Figure 6 with respect to the reaction temperature. The increase in temperature linearly increases the STY from $263 \mathrm{~g} / \mathrm{Kg}$ cat $/ \mathrm{hr}$ to $600 \mathrm{~g} / \mathrm{Kg}_{\text {cat }} / \mathrm{hr}$ for temperatures ranging from $280{ }^{\circ} \mathrm{C}$ to $300{ }^{\circ} \mathrm{C}$. For the temperatures tested, the product composition typically contained carbon dioxide $\left(\mathrm{CO}_{2}\right)$ between $2 \%$ and $3.5 \%, \mathrm{CH}_{4}$ between $14.9 \%$ and $17.9 \%, \mathrm{C}_{2}-\mathrm{C}_{6}$ alkanes between $13.9 \%$ and $19.2 \%, \mathrm{C}_{2}-\mathrm{C}_{6}$ alkenes between $31.5 \%$ and $38.5 \%$, hydrocarbon liquids between $20.3 \%$ and $26.2 \%$, which contains the combination of $\mathrm{C}_{6}+$ alkanes and $\mathrm{C}_{6}+$ alkenes along with small quantities of dissolved small olefins, paraffins, and oxygenates, and the oxygenates composition between $4.3 \%$ and $7 \%$.

The CO conversion increases along with the temperature (as seen with the STY). Donnelly and Satterfield (1989) reported that an increase in temperature results in a tendency toward products with a lower carbon number on Fe-, $\mathrm{Ru}-$, and Co- (Dry, 1981) based catalysts. In this study, there

was little change in the product distribution with respect to the carbon number between the temperature ranges of $280^{\circ} \mathrm{C}$ to $295^{\circ} \mathrm{C}$. 


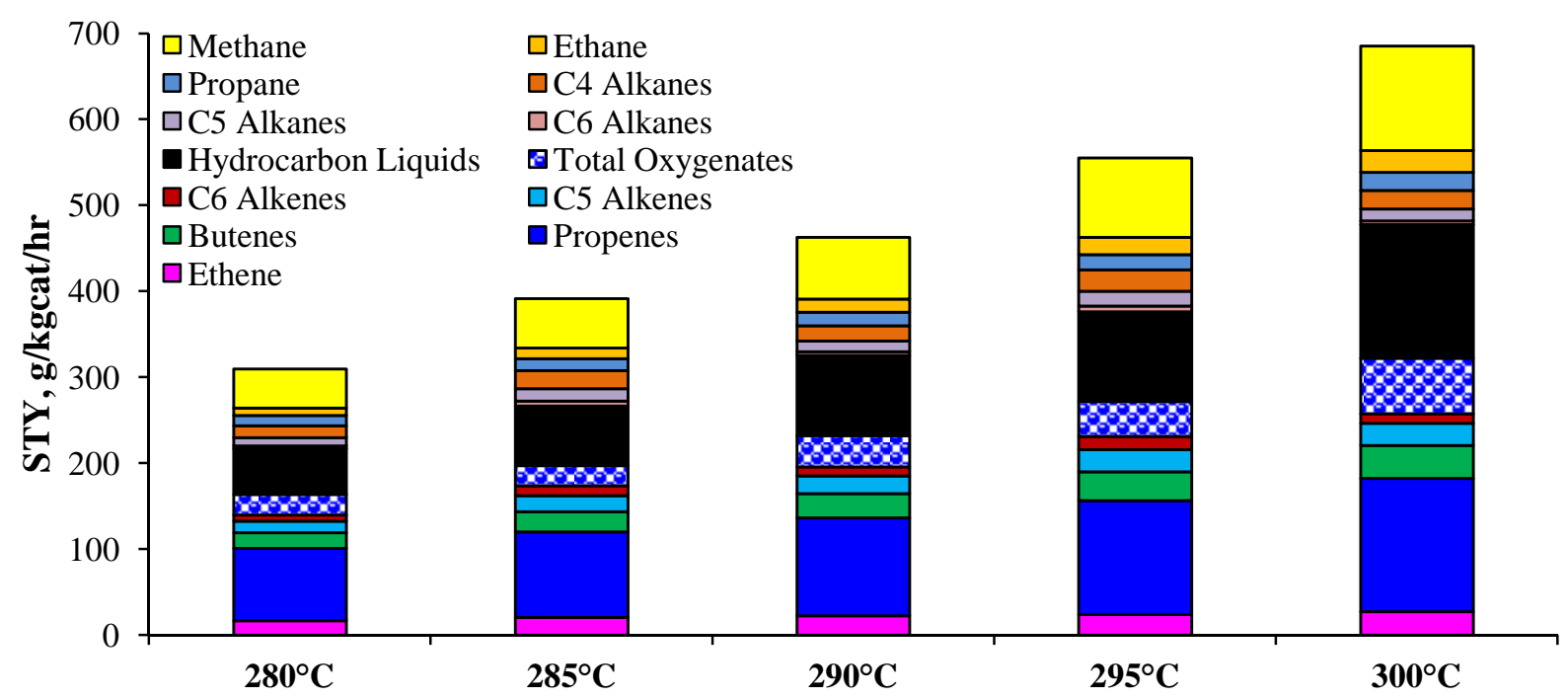

Fig. 5. STY and the product distribution at different reaction temperatures over the $2.9 \%$ Co$2.9 \% \mathrm{Ni}$ bimetallic catalyst at $1200 \mathrm{psi}, \mathrm{H}_{2}$ to $\mathrm{CO}$ ratio of 2 , and GHSV $12000 \mathrm{~L} / \mathrm{Kg} / \mathrm{hr}$ operating conditions.

Van Der Laan et al. (1999) reported that the carbon number distributions for hydrocarbons give the highest concentration for $\mathrm{CH}_{4}$, with a local maximum detected around the $\mathrm{C}_{3}$ hydrocarbon for the FTS on typical Co, Fe, and Ru catalysts. Figure 6 depicts the selectivity of paraffin and olefin composition, and the olefin to paraffin ratio generated from the $\mathrm{CO}$ hydrogenation experiment conducted over the Co-Ni catalyst at $300{ }^{\circ} \mathrm{C}, \mathrm{H}_{2}$ to $\mathrm{CO}$ ratio of 2 , GHSV $12000 \mathrm{~L} / \mathrm{Kg} / \mathrm{hr}$, and 1200 psi operating conditions.

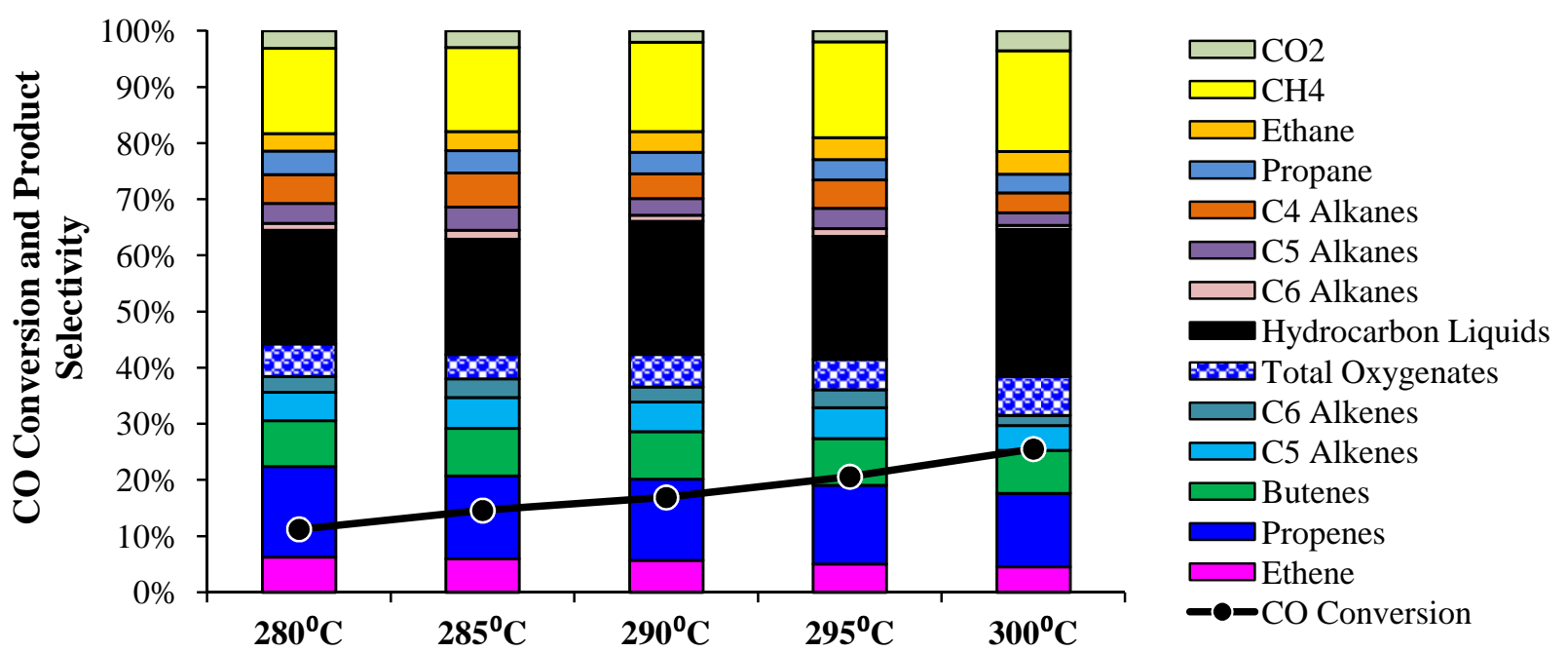

Fig. 6. $\mathrm{CO}$ conversion and product selectivity at different reaction temperature over the $2.9 \% \mathrm{Co}-$ $2.9 \% \mathrm{Ni}$ bimetallic catalyst at $1200 \mathrm{psi}, \mathrm{H}_{2}$ to $\mathrm{CO}$ ratio 2, and GHSV $12000 \mathrm{~L} / \mathrm{Kg} / \mathrm{hr}$ operating conditions.

A notable reduction in the small carbon number was identified for the $300{ }^{\circ} \mathrm{C}$ experiment; this was compensated by the increased selectivity towards the hydrocarbon liquids and oxygenates composition for the Co-Ni bimetallic catalyst. This differed from the literature described above 
for the monometallic catalyst. Similar behavior of selectivity shifted towards a heavier hydrocarbon at higher temperatures was reported by de la Peña O'Shea et al. (2007) for the FTS chemistry on the Fe-Co bimetallic catalyst.

Our results are similar to those reported by Van Der Laan et al. (1999), with the exception of the $\mathrm{C}_{3}$ composition being among the highest including the $\mathrm{CH}_{4}$ composition. It is reported in the literature that 1-alkenes are primary products of the FTS reaction over a Fe-based catalyst, and they potentially undergo a secondary hydrogenation reaction to generate paraffins (Nakhaei Pour and Housaindokht, 2013; Schulz, 2003; Schulz et al., 1988; Li et al., 2002). It has also been shown that the secondary hydrogenation increases with carbon number due to increased adsorption strength. Ethylene appeared to be very reactive for hydrogenation relative to heavier olefins. The selectivity of paraffin, olefin, and the olefin to paraffin ratio generated from the $\mathrm{CO}$ hydrogenation experiment conducted experiment conducted over the $2.9 \% \mathrm{Co}-2.9 \% \mathrm{Ni}$ catalyst at $300{ }^{\circ} \mathrm{C}, \mathrm{H}_{2}$ to $\mathrm{CO}$ ratio 2, GHSV $12000 \mathrm{~L} / \mathrm{Kg} / \mathrm{hr}$, and 1200 psi operating conditions is shown ib Figure 7.For the Co-Ni bimetallic catalyst, the olefin to paraffin ratio was close to 8 for the $\mathrm{C}_{3}$ hydrocarbon, and was around 1.6 for $\mathrm{C}_{4}$ through $\mathrm{C}_{11}$. At $\mathrm{C}_{11}+$, the olefin to paraffin ratio starts to drop slowly. As shown in the literature, the $\mathrm{C}_{2}$ olefin to paraffin ratio was low, at around 1 .

The carbon number distribution for the products generated from the FTS synthesis can be determined by the chain growth probability $(\alpha)$ calculated from the Anderson-Schultz-Flory (ASF) equation. The $\alpha$ value can be influenced by variables such as catalyst composition, operating conditions, syngas composition, and the types of reactor used (Dry, 2004 p.196). Based on the ASF model prediction for the FTS reaction, the maximum selectivity towards the $\mathrm{C}_{2}$ to $\mathrm{C}_{4}$ olefins can be achieved with an $\alpha$ value between 0.4 and 0.5 (Torres Galvis and de Jong, 2013). In our experiments of the Co-Ni bimetallic catalyst, it was demonstrated to achieve the low $\alpha$ value, or in other words a high $\mathrm{C}_{2}$ to $\mathrm{C}_{4}$ olefin selectivity for the higher reaction temperature. However, this increase in small olefin selectivity results in an increase in undesired $\mathrm{CH}_{4}$ selectivity (Janardanarao, 1990).

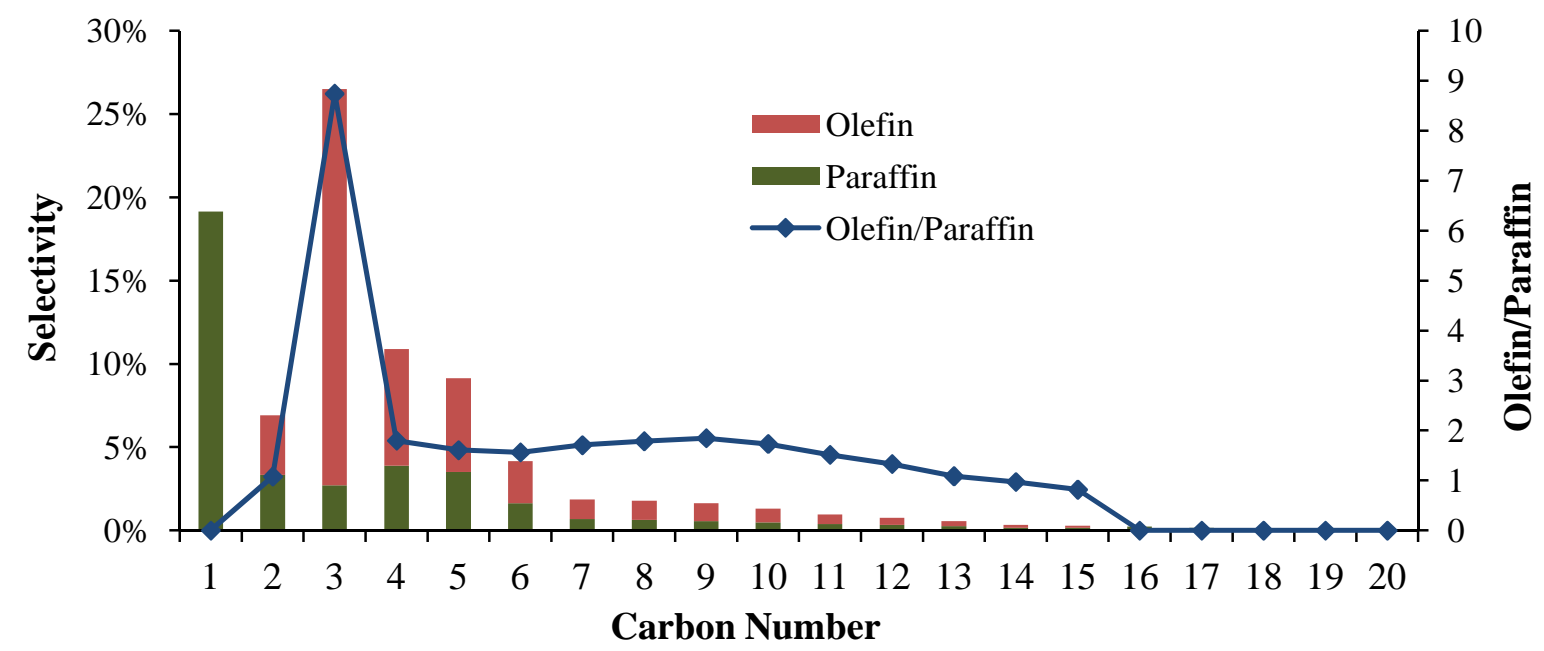

Fig. 7. Selectivity of paraffin, olefin, and the olefin to paraffin ratio generated from the $\mathrm{CO}$ hydrogenation experiment conducted over the $2.9 \% \mathrm{Co}-2.9 \% \mathrm{Ni}$ catalyst at $300{ }^{\circ} \mathrm{C}, \mathrm{H}_{2}$ to $\mathrm{CO}$ ratio 2, GHSV $12000 \mathrm{~L} / \mathrm{Kg} / \mathrm{hr}$, and 1200 psi operating conditions. 
The ASF plot for the hydrocarbon distribution generated during the $\mathrm{CO}$ hydrogenation over Co$\mathrm{Ni}$ on a $\mathrm{SiO}_{2}$ catalyst at $300{ }^{\circ} \mathrm{C}$ with $\mathrm{H}_{2}$ to $\mathrm{CO}$ ratio of 2 at $1200 \mathrm{psi}$ and at $12000 \mathrm{~L} / \mathrm{Kg} / \mathrm{hr} \mathrm{GHSV}$ is shown in Figure 8. For these conditions, the calculated $\alpha$ value for the $\mathrm{C}_{5}+$ product composition is around 0.37 . Dry (1982) reported the typical range of $\alpha$ values for a Ru catalyst is between 0.85 and 0.95 , the typical range for a Co catalyst is between 0.7 and 0.8 , and the typical range for an Fe catalyst is between 0.5 and 0.7. Literature also shows that a large deviation in the $\alpha$ value is observed for operating temperatures greater than $280{ }^{\circ} \mathrm{C}$ (Lox and Froment, 1993; Everson et al., 1978). Our results are better aligned with the reported results (i.e., a lower $\alpha$ value and increased small olefin selectivity).

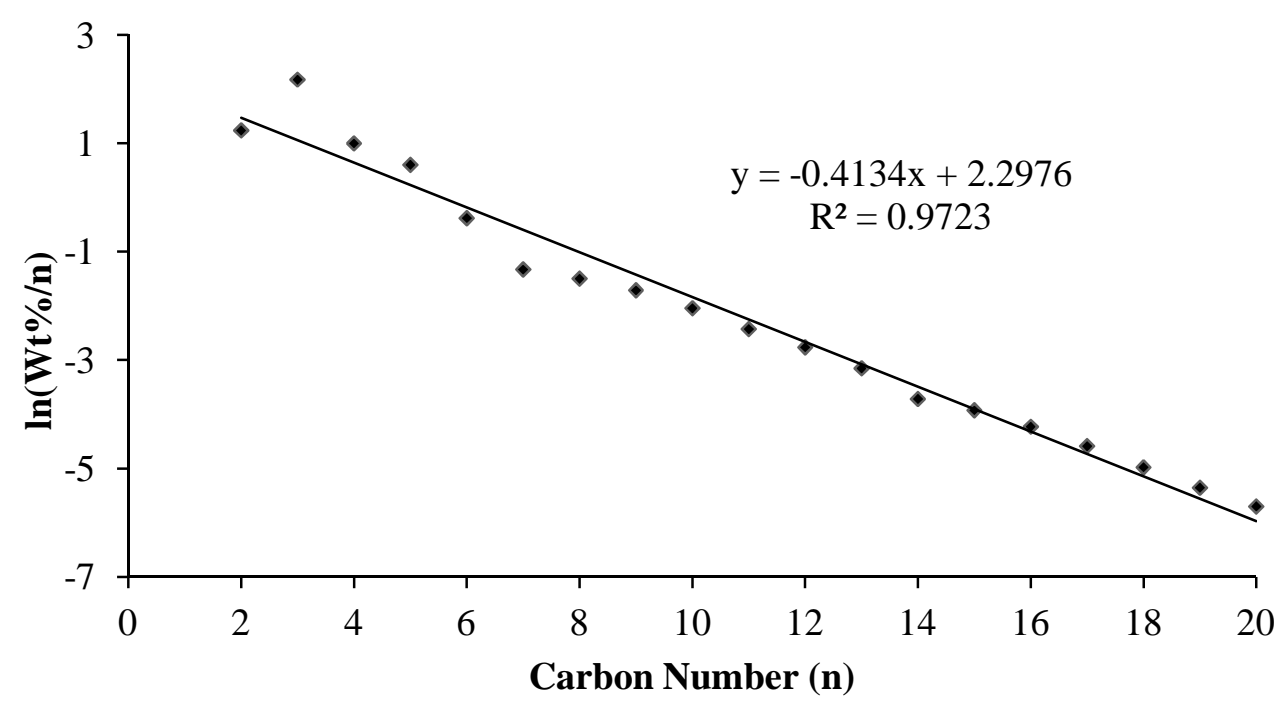

Fig. 8. ASF plot for the hydrocarbon distribution generated during the $\mathrm{CO}$ hydrogenation over $2.9 \% \mathrm{Co}-2.9 \% \mathrm{Ni}$ on a $\mathrm{SiO} 2$ catalyst at $300{ }^{\circ} \mathrm{C}, \mathrm{H}_{2}$ to $\mathrm{CO}$ ratio $2,1200 \mathrm{psi}$ and at $12000 \mathrm{~L} / \mathrm{Kg} / \mathrm{hr}$ GHSV.

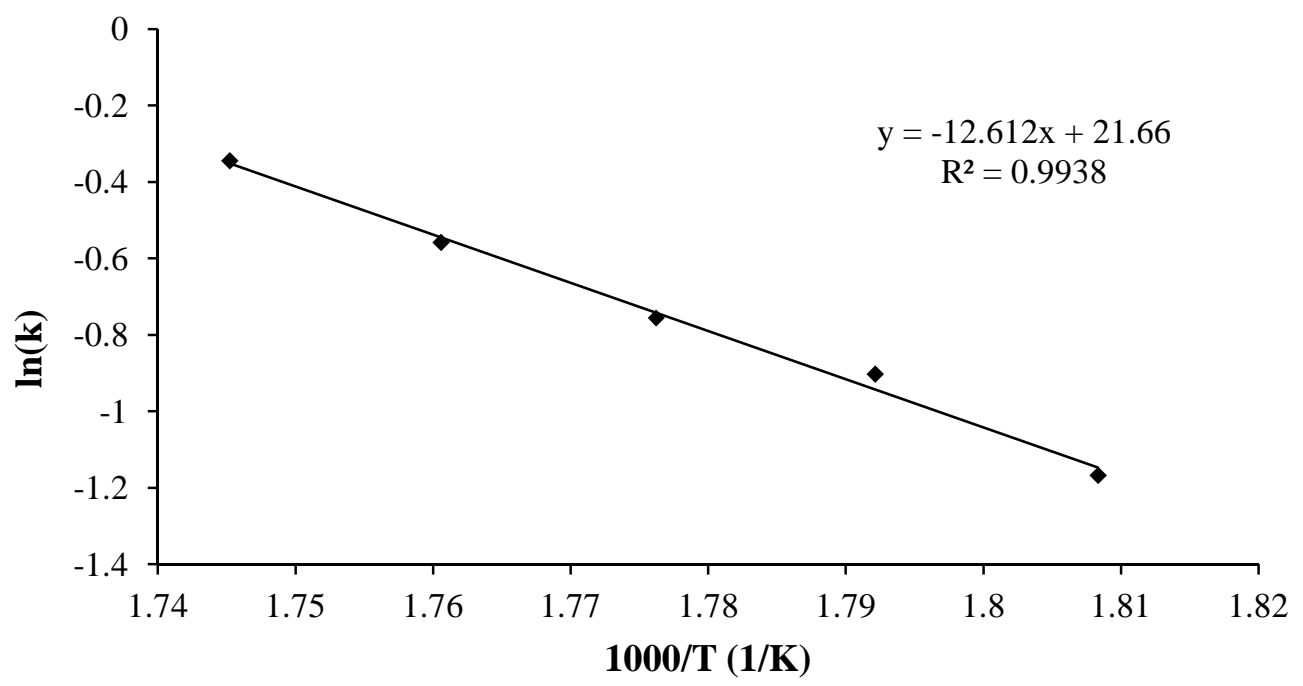

Fig. 9. Arrhenius plot for the $\mathrm{CO}$ conversion rate during the $\mathrm{CO}$ hydrogenation over $2.9 \% \mathrm{Co}-$ $2.9 \% \mathrm{Ni}$ on a silica catalyst at $1200 \mathrm{psi}, \mathrm{H}_{2}$ to $\mathrm{CO}$ ratio 2 , and at $12000 \mathrm{~L} / \mathrm{Kg} / \mathrm{hr} \mathrm{GHSV}$. 
Figure 9 shows the Arrhenius plot for the $\mathrm{CO}$ conversion rate during the $\mathrm{CO}$ hydrogenation over Co-Ni on a silica catalyst at $1200 \mathrm{psi}, \mathrm{H}_{2}$ to $\mathrm{CO}$ ratio 2, and at $12000 \mathrm{~L} / \mathrm{Kg} / \mathrm{hr} \mathrm{GHSV}$. The Arrhenius plot of the $\mathrm{CO}$ conversion rate plotted for the temperature range between $280{ }^{\circ} \mathrm{C}$ and $300{ }^{\circ} \mathrm{C}$ generated a straight line and shows apparent activation energy of $104 \mathrm{KJ} / \mathrm{mol}$. This apparent activation energy value is similar to the reported values for the FTS process utilizing different catalyst compositions (Yates and Satterfield, 1991; Arsalanfar et al., 2012).

\subsection{Higher Metal Loading}

Initial testing shows that there are beneficial operational parameters that can be varied to improve the activity and selectivity of the baseline catalyst, but some of these parameters, especially temperature, promote undesirable $\mathrm{CH}_{4}$ production and minimize wax formation. Also, increased temperature leads to an increase in $\mathrm{CO}_{2}$ production. Because these reactions seem to be more dependent on temperature than other parameters, an investigation was performed to look at increased metal loading to retain the amplified activity and decrease the temperature. Figure 10 and Figure 11 shows that comparable results can be achieved at much lower temperatures with a catalyst composition double $(5.8 \% \mathrm{Co}-5.8 \% \mathrm{Ni})$ that of the initial baseline catalyst. The STY and the $\mathrm{CO}$ conversion levels, as well as the selectivities, were comparable for the $280{ }^{\circ} \mathrm{C}$ experiment conducted over $2.9 \% \mathrm{Co}-2.9 \% \mathrm{Ni}$ loaded on $\mathrm{S} \mathrm{SiO}_{2}$ support (shown in Figure 5 and Figure 6) and the $250{ }^{\circ} \mathrm{C}$ experiment conducted over the catalyst containing twice the metal loading. Beyond $250{ }^{\circ} \mathrm{C}$, the STY and CO conversion move in the right direction, but the selectivity to the small carbon number olefins drops dramatically and the higher temperature tends to generate high levels of hydrocarbon liquids containing $\mathrm{C}_{6}+$ paraffins.

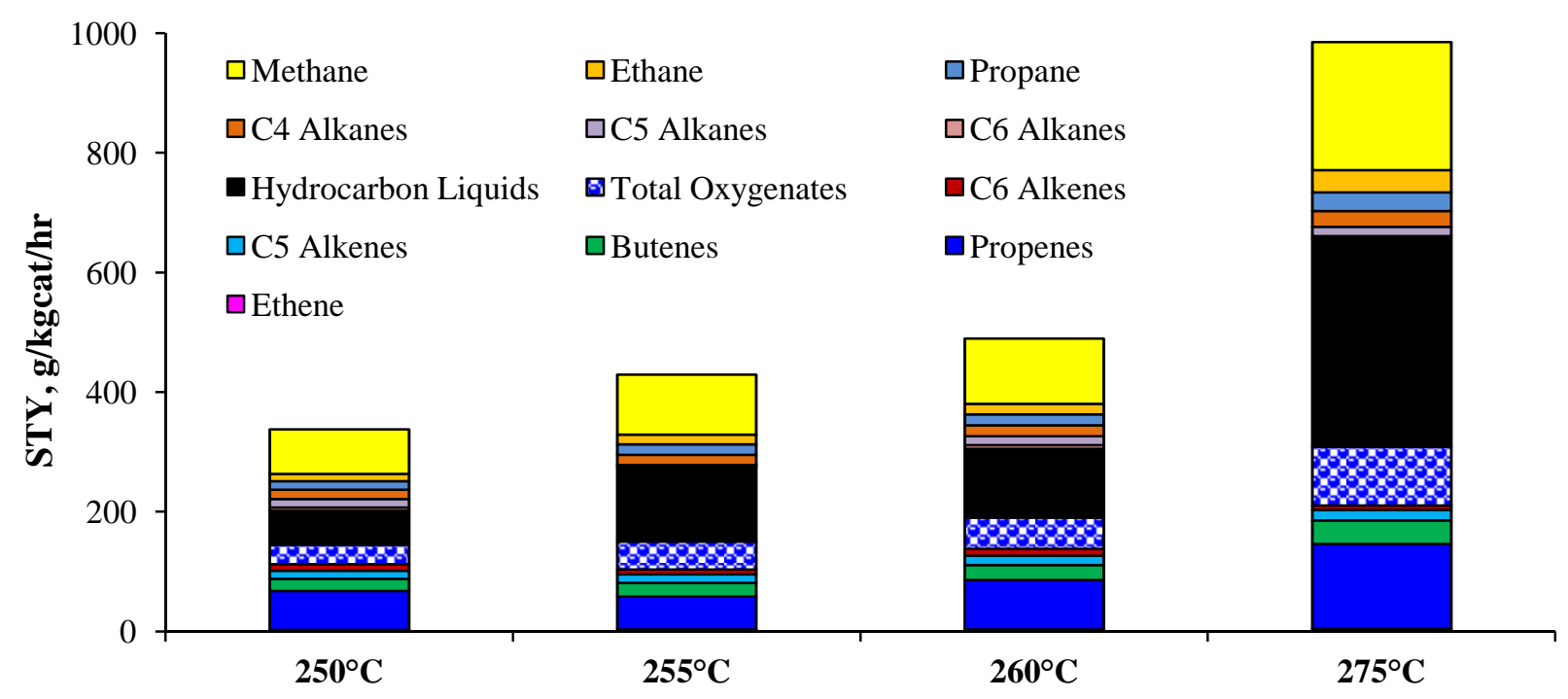

Fig. 10. STY and the product distribution for $5.8 \% \mathrm{Co}-5.8 \% \mathrm{Ni}$ ( $2 \mathrm{X}$ the normal metal loading of $\mathrm{Co}$ and $\mathrm{Ni}$ ) at various temperatures, $\mathrm{H}_{2}$ to $\mathrm{CO}$ ratio 2, GHSV $12000 \mathrm{~L} / \mathrm{Kg} / \mathrm{hr}$, and 1200 psi operating conditions.

Figure 12 shows the Arrhenius plot for the $\mathrm{CO}$ conversion rate during the $\mathrm{CO}$ hydrogenation over the $5.8 \% \mathrm{Co}-5.8 \% \mathrm{Ni}$ metal loading on a silica catalyst at $1200 \mathrm{psi}, \mathrm{H}_{2}$ to $\mathrm{CO}$ ratio 2 , and at $12000 \mathrm{~L} / \mathrm{Kg} / \mathrm{hr}$ GHSV. The Arrhenius plot of the CO conversion rate plotted for the temperature range between $250{ }^{\circ} \mathrm{C}$ and $275^{\circ} \mathrm{C}$ generated a straight line and shows an apparent activation 
energy of $103 \mathrm{KJ} / \mathrm{mol}$. This apparent activation energy is very similar to the lower metal loading experiments, as well as the reported literature values.

FTS experiments were also conducted over the catalyst containing both three times and four times the normal metal loading at various temperatures. These experiments generated very high levels of wax in the product composition. The high metal loading results were not reported here because the high wax generation made it difficult to collect the samples properly.

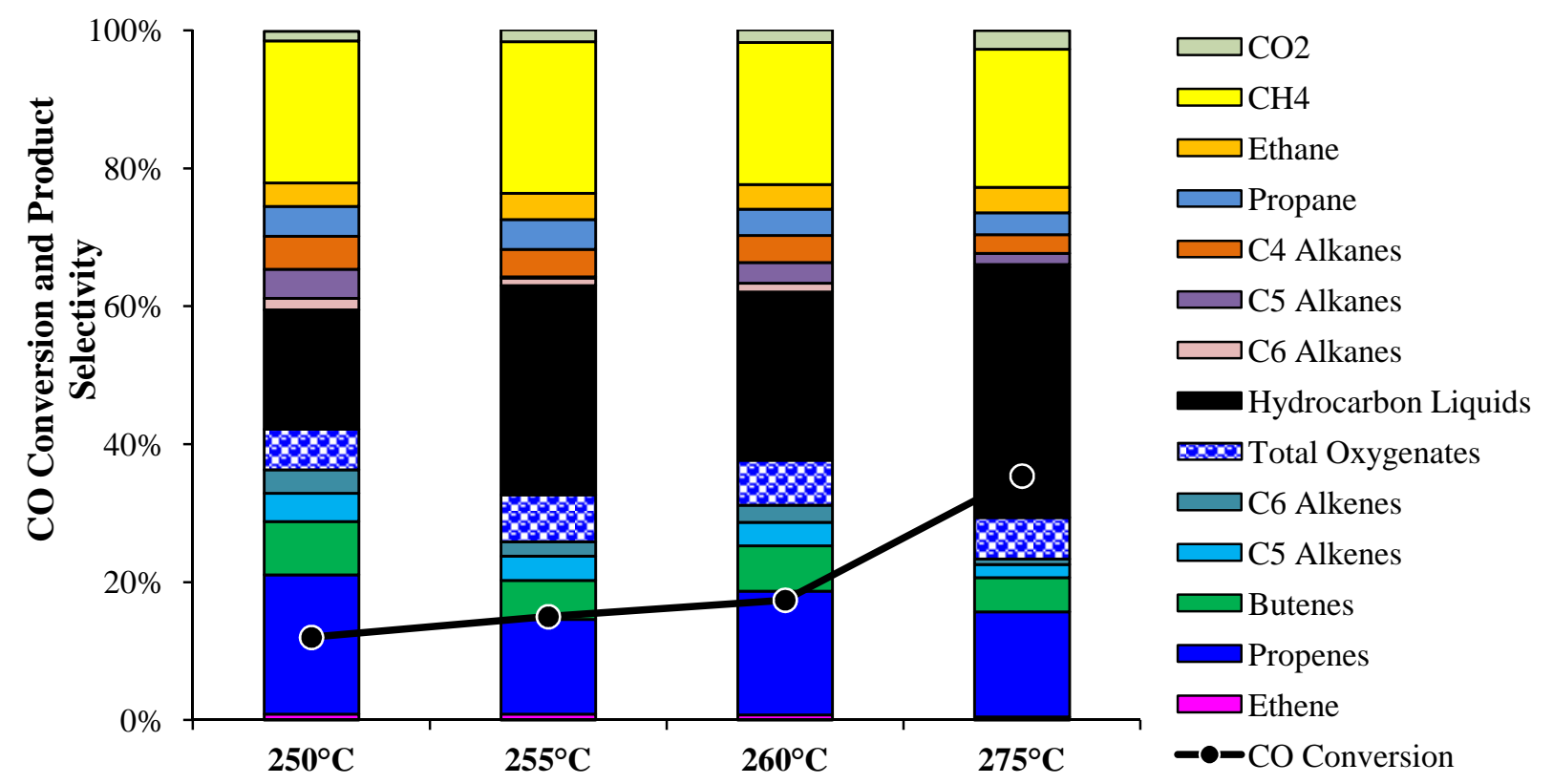

Fig. 11. $\mathrm{CO}$ conversion and product selectivity for $5.8 \% \mathrm{Co}-5.8 \% \mathrm{Ni}(2 \mathrm{X}$ the normal metal loading of $\mathrm{Co}$ and $\mathrm{Ni}$ ) at various temperature, $\mathrm{H}_{2}$ to $\mathrm{CO}$ ratio 2, GHSV $12000 \mathrm{~L} / \mathrm{Kg} / \mathrm{hr}$, and 1200 psi operating conditions.

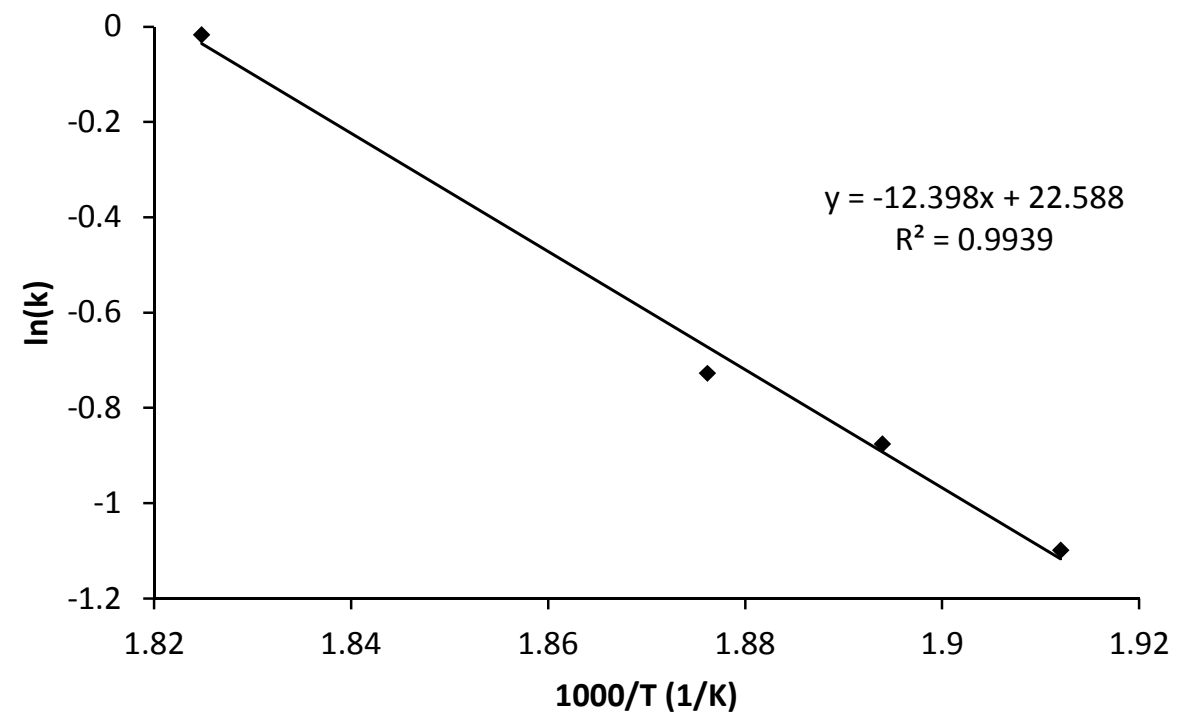

Fig. 12. Arrhenius plot for the $\mathrm{CO}$ conversion rate during the $\mathrm{CO}$ hydrogenation over $5.8 \% \mathrm{Co}-$ $5.8 \% \mathrm{Ni}$ on $\mathrm{SiO}_{2}$ catalyst, $\mathrm{H}_{2}: \mathrm{CO}$ ratio 2, $1200 \mathrm{psi}$, and at $12000 \mathrm{~L} / \mathrm{Kg} / \mathrm{hr} \mathrm{GHSV}$. 


\subsection{Dual Reactor Arrangement for the Oxygenate Conversion}

Initial testing on the $2.9 \% \mathrm{Co}-2.9 \% \mathrm{Ni}$ bimetallic baseline catalyst showed the catalyst to be beneficial for converting syngas to a mixture of olefins, paraffins, and oxygenates (the primary focus was on a high olefin-to-paraffin ratio, especially for the low molecular weight paraffins and olefins region). Striving to achieve high olefin selectivity, it would be desirable to further convert oxygenated compounds in the product mixture via deoxygenation (preferentially via a dehydration mechanism) to increase the yield of a hydrocarbon product. Acidic catalysts are very useful in dehydration reactions of oxygenated products, particularly when the oxygenates are composed primarily of alcohols (Jain and Pillai, 1967). The tests were performed to determine if the heterogeneous acidic catalysts were active in converting the minor oxygenates along with the mixture containing a large amount of hydrocarbons, water, and unconverted $\mathrm{CO}$ and $\mathrm{H}_{2}$. Figure 13 shows the simple schematic representation of the dual bed configuration containing a Co-Ni based $\mathrm{CO}$ hydrogenation catalyst followed by an acidic alumina catalyst.

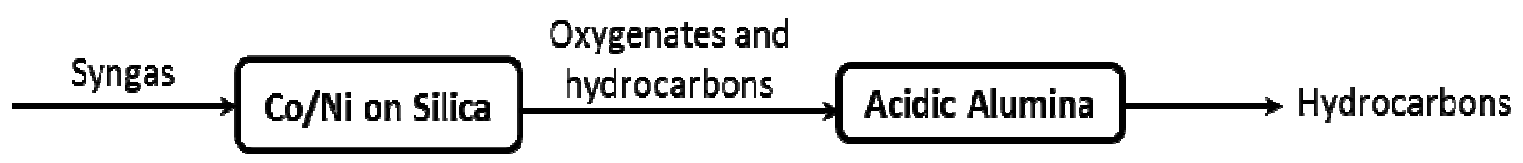

Fig. 13. Representation of the dual bed configuration to convert the oxygenates to hydrocarbons.

Table 2 lists the $\mathrm{CO}$ hydrogenation performance comparison between single bed (Co-Ni on silica) and dual bed (Co-Ni on a silica catalyst bed followed by an acidic alumina catalyst bed) reactor configurations and the operating conditions. The results show that over an acidic alumina catalyst, a single-pass conversion of the oxygenate mixture was close to $90 \%$, reducing the oxygenate selectivity in the products from $10 \%$ to approximately $1 \%$. The olefinic and the paraffinic composition was increased to compensate the drop in oxygenate concentration, particularly the increase in the ethylene levels, showing the direct dehydration of ethanol (primary oxygenate compound) on the acidic alumina catalyst. The product distribution of the dual bed reactor also contains high levels of $\mathrm{CO}_{2}$, increasing from $4 \%$ to $10.2 \%$ compared to the single bed reactor. The liquid oxygenate composition from the Co-Ni reactor primarily contains alcohols and minor levels of aldehyde and carboxylic acid contents. Therefore, the alcohols are expected to go through the direct dehydration mechanism to form the parent olefinic compounds and the minor levels of aldehyde and carboxylic compounds are expected to form carbon oxides in small quantities from the decarboxylation, decarbonylation and decomposition pathway. However, the nature of the various functional groups present in the oxygenate fraction, along with the presence of water and hydrocarbon compounds, makes the deoxygenation chemistry more complex (Ramasamy et al., Green Chem., 2014). To understand the role of the stainless tube reactor at $350{ }^{\circ} \mathrm{C}$, an experiment was conducted at $350{ }^{\circ} \mathrm{C}$ using the Co-Ni catalyst in the first bed, followed by the empty bed. This experiment showed increased levels of $\mathrm{CO}_{2}$ in the dual bed product composition compared to the single bed product composition. This explains the potential water gas shift activity of the stainless steel reactor wall, which also played a role in the increased $\mathrm{CO}_{2}$ levels. These initial experiments demonstrate the potential of the oxygenate conversion to respective olefins using a low-cost acidic catalyst downstream to the FTS reactor. Further development of the bi-functional catalyst is required to convert the complex oxygenates to valuable olefinic compounds and improve the carbon efficiency of the process. 
Table 2. CO hydrogenation performance comparison between single bed $(2.9 \% \mathrm{Co}-2.9 \% \mathrm{Ni}$ on $\left.\mathrm{SiO}_{2}\right)$ and dual bed $\left(2.9 \% \mathrm{Co}-2.9 \% \mathrm{Ni}\right.$ on $\mathrm{SiO}_{2}$ catalyst bed followed by an acidic alumina catalyst bed) configurations."

\begin{tabular}{lcc}
\hline & Single Bed Reactor & Dual Bed Reactor \\
\hline Catalysts & Co-Ni on Silica & Co-Ni on Silica $\rightarrow$ Acidic Alumina \\
$\mathrm{CO}$ Conversion, \% & 19.4 & 20.0 \\
$\mathrm{CO}_{2}$ Selectivity, \% & 4.0 & 10.1 \\
$\mathrm{CH}_{4}$ Selectivity, \% & 19.1 & 18.6 \\
$\mathrm{C}_{2}-\mathrm{C}_{7}$ Paraffin Selectivity, \% & 14.8 & 13.0 \\
$\mathrm{C}_{2}-\mathrm{C}_{7}$ Olefin Selectivity, \% & 43.8 & 45.8 \\
$\mathrm{C}_{8}-\mathrm{C}_{14}$ Paraffin Selectivity, $\%$ & 2.84 & 4.9 \\
$\mathrm{C}_{8}-\mathrm{C}_{14}$ Olefin Selectivity, \% & 4.5 & 5.0 \\
$\mathrm{C}_{14}$ - Paraffin Selectivity, \% & 0.9 & 0.9 \\
$\mathrm{C}_{14}$ Olefin Selectivity, \% & 0.1 & 0.1 \\
Olefin to Paraffin Ratio (O/P) & 2.6 & 2.7 \\
Oxygenates, \% & 10.0 & 1.3 \\
\hline
\end{tabular}

${ }^{*}$ Reactions conducted at $300^{\circ} \mathrm{C}$ on the Co-Ni on Silica and $350^{\circ} \mathrm{C}$ on the Acidic Alumina (dual bed reactor setup), at $1200 \mathrm{psi}$ and at $12000 \mathrm{~L} / \mathrm{Kg} / \mathrm{hr}$ GHSV

\section{Conclusion}

Co-Ni bimetallic catalysts show promise for converting syngas produced from biomass and other low-value material, such as municipal solid waste (via gasification technologies), to valuable compounds. There are many improvements that can be made to the Co-Ni bimetallic catalysts by optimizing the catalyst preparation procedure, such as calcination temperatures, catalyst loadings, different promoters, and other operational parameters particularly focused on reducing the $\mathrm{CH}_{4}$ composition with a high olefin to paraffin ratio. Increasing activity and selectivity to the desired products will allow an ease in downstream processing technologies and increase overall carbon efficiency. Avoiding the oxygenate compounds generation completely from the syngas hydrogenation is very difficult. However, by combining syngas hydrogenation with acidic catalysts in a multi-step conversion process, the low levels of oxygenates can be converted to the small olefinic composition, but further development of the bi-functional catalyst is required to reduce the impact of the undesired side reaction.

\section{Acknowledgements}

The Pacific Northwest National Laboratory is operated by the Battelle Memorial Institute for the U.S. Department of Energy under contract no. DE-AC05-76RL01830. This work was supported by the U.S. Department of Energy's Bioenergy Technology Office. The authors wish to express thanks to Robert A. Dagle and Michael A. Lilga for the valuable technical discussions, Colin D. Smith for the XRD analysis, and Xiaohong Shari Li for the BET analysis.

\section{References}

Arsalanfar M, Mirzaei A A, Atashi H, Bozorgzadeh H R, Vahid S, Zare A,. 2012, An investigation of the kinetics and mechanism of Fischer-Tropsch synthesis on Fe-Co-Mn supported catalyst. Fuel Process Technol., 96, 150-159. 


\section{Revised Manuscript}

Calderone, V.R., Shiju, N.R., Ferré, D.C., Rothenberg, G., 2011. Bimetallic catalysts for the Fischer-Tropsch reaction. Green Chem,, 13, 1950.

Chang, J., Sun, J., Xu, C., Xu, H., Gao, L., 2012. Template-free approach to synthesize hierarchical porous nickel cobalt oxides for supercapacitors. Nanoscale 4, 6786-6791.

de Smit, E., Weckhuysen, B.M., 2008. The renaissance of iron-based Fischer-Tropsch synthesis: on the multifaceted catalyst deactivation behaviour. Chem. Soc. Rev., 37, 2758-2781.

de la Peña O'Shea, V.A., Álvarez-Galván, M.C., Campos-Martín, J.M., Fierro, J.L.G., 2007. Fischer-Tropsch synthesis on mono- and bimetallic Co and Fe catalysts in fixed-bed and slurry reactors. Appl. Catal. A-Gen., 326, 65-73.

Donnelly, T.J., Satterfield, C.N., 1989. Product Distributions of the Fischer-Tropsch Synthesis on Precipitated Iron Catalysts. Appl. Catal., 52, 93-114.

Dry M. E., in Catalysis-Science and Technology (J. R. Anderson and M. Boudart, eds.), Springer-Verlag, New York, 1981, Vol. 1, 160-255.

Dry, M.E., 1982. Catalytic Aspects of Industrial Fischer-Tropsch Synthesis. J. Mol. Catal., 17, 133-144.

Dry, M.E., 2004. Chemical concepts used for engineering purposes, Stud. Surf. Sci. Catal., 152, 196-257.

Dry, M.E., 2004. FT Catalysts, in: Stud. Surf. Sci. Catal., 152, 533-600.

Enger, B.C., Holmen, A., 2012. Nickel and Fischer-Tropsch Synthesis. Cat. Rev. - Sci. Eng., 54, 437-488.

Everson, R.C., Woodburn, E.T., Kirk, A.R.M., 1978. Fischer-Tropsch reaction studies with supported ruthenium catalysts: I. Product distributions at moderate pressures and catalyst deactivation. J. Catal., 53, 175-285.

Feyzi, M., Babakhanian, A., Gholivand, M.B., 2013. Catalytic performance and characterization of cobalt-nickel nano catalysts for CO hydrogenation. Korean J. Chem. Eng. 31, 37-44.

Gnanamani, M.K., Jacobs, G., Shafer, W.D., Davis, B.H., 2013. Fischer-Tropsch synthesis: Activity of metallic phases of cobalt supported on silica. Catal. Today., 215, 13-17.

Hu, D., Gao, J., Ping, Y., Jia, L., Gunawan, P., Zhong, Z., Xu, G., Gu, F., Su, F., 2012. Enhanced Investigation of CO Methanation over Ni/Al2O3Catalysts for Synthetic Natural Gas Production. Ind. Eng. Chem. Res., 51, 4875-4886. 


\section{Revised Manuscript}

Jahangiri, H., Bennett, J., Mahjoubi, P., Wilson, K., Gu, S., 2014. A review of advanced catalyst development for Fischer-Tropsch synthesis of hydrocarbons from biomass derived syn-gas. Catal. Sci. Technol., 4, 2210-2229.

Jain, J.R., Pillai, C.N., 1967. Catalytic Dehydration of Alcohols over Alumina Mechanism of Ether Formation. J. Catal., 9, 322-330.

Janardanarao, M., 1990. Direct Catalytic Conversion of Synthesis Gas to Lower Olefins. Ind. Eng. Chem. Res., 29, 1735-1753.

Li, S., Krishnamoorthy, S., Li, A., Meitzner, G.D., Iglesia, E., 2002. Promoted iron-based catalysts for the FischereTropsch synthesis: design, synthesis, site densities, and catalytic properties. J. Catal., 206, 202-217.

Li, L., Lu, P., Yao, Y., Ji, W., 2012. Silica-encapsulated bimetallic Co-Ni nanoparticles as novel catalysts for partial oxidation of methane to syngas. Catal. Commun., 26, 72-77.

Liang, Q., Chen, K.D., Hou, W.H., Yan, Q.J., 1998. CO hydrogenation over nanometer spineltype Co/Mn complex oxides prepared by sol-gel method. Appl. Catal. A-Gen., 166, 191-199.

Lox, E.S., Froment, G.F., 1993. Kinetics of the Fischer-Tropsch Reaction on a Precipitated Promoted Iron Catalyst .1. Experimental Procedure and Results. Ind. Eng. Chem. Res., 29 32, 61-70.

Luisetto, I., Tuti, S., Di Bartolomeo, E., 2012. Co and Ni supported on $\mathrm{CeO} 2$ as selective bimetallic catalyst for dry reforming of methane. Int. J. Hydrogen Energy., 37, 15992-15999.

Nakhaei Pour, A., Housaindokht, M.R., 2013. The olefin to paraffin ratio as a function of catalyst particle size in Fischer-Tropsch synthesis by iron catalyst. Journal of Natural Gas Science and Engineering., 14, 204-210.

Oliveira, H.A., Franceschini, D.F., Passos, F.B., 2012. Support Effect on Carbon Nanotube Growth by Methane Chemical Vapor Deposition on Cobalt Catalysts. J. Brazil. Chem. Soc., 23, 868-879.

Ponec V., 1978. Some Aspects of the Mechanism of Methanation and Fischer-Tropsch Synthesis Catal. Rev.-Sci. Eng., 18, 151-171.

Ramasamy, K.K., Wang, Y., 2014. Ethanol conversion to hydrocarbons on HZSM-5: Effect of reaction conditions and Si/Al ratio on the product distributions. Catal. Today., 237, 89-99.

Ramasamy, K.K., Gerber, M.A., Flake, M., Zhang, H., Wang, Y., 2014. Conversion of biomassderived small oxygenates over HZSM-5 and its deactivation mechanism. Green Chem., 16, 748760 . 


\section{Revised Manuscript}

Roferdepoorter, C.K., 1981. A Comprehensive Mechanism for the Fischer-Tropsch Synthesis. Chem. Rev., 81, 447-474.

Rytter, E., Skagseth, T.H., Eri, S., Sjåstad, A. O., 2010. Cobalt Fischer-Tropsch Catalysts Using Nickel Promoter as a Rhenium Substitute to Suppress Deactivation. Ind. Eng. Chem. Res., 49(9), 4140-4148.

Sarup, S., Wojciechowski B. W., 1988, Studies of the fischer-tropsch synthesis on a cobalt catalyst i. evaluation of product distribution parameters from experimental data. Can. J. Chem. Eng., 66, 831-842.

Schulz, H., Beck, K., Erich, E., 1988. Mechanism of the Fischer Tropsch process. Stud. Surf. Sci. Catal., Elsevier, 36, 457-471.

Schulz, H., 2003. Major and minor reactions in FischereTropsch synthesis on cobalt catalysts. Top. Catal., 26, 73-85.

Torres Galvis, H.M., de Jong, K.P., 2013. Catalysts for Production of Lower Olefins from Synthesis Gas: A Review. ACS Catalysis., 3, 2130-2149.

Van Der Laan, G.P., Beenackers, A.A.C.M., 1999. Kinetics and Selectivity of the FischerTropsch Synthesis: A Literature Review. Cat. Rev., 41, 255-318.

vanSteen, E., Sewell, G.S., Makhothe, R.A., Micklethwaite, C., Manstein, H., deLange, M., OConnor, C.T., 1996. TPR study on the preparation of impregnated Co/SiO2 catalysts. J. Catal., $162,220-229$.

Yates I. C, Satterfield C. N,. 1991, Fischer-Tropsch synthesis on a cobalt catalyst. Energy Fuels., 5, 168-173.

Zhang, Q., Kang, J., Wang, Y., 2010. Development of Novel Catalysts for Fischer-Tropsch Synthesis: Tuning the Product Selectivity. Chem.Cat.Chem., 2, 1030-1058.

Zhao, A., Ying, W., Zhang, H., Ma, H., Fang, D., 2012. Ni-A12O3 catalysts prepared by solution combustion method for syngas methanation. Catal. Commun., 17, 34-38.

Zhou, W.-G., Liu, J.-Y., Wu, X., Chen, J.-F., Zhang, Y., 2015. An effective Co/MnOx catalyst for forming light olefins via Fischer-Tropsch synthesis. Catal. Commun., 60, 76-81. 